\title{
CYSTIC DEGENERATION IN FOLLICULAR AMELOBLASTOMA: A CASE REPORT
}

Neeraj Kumar ${ }^{1}$, Niharika Rathore ${ }^{2}$, Hemant Shakya ${ }^{3}$, Anshuman Jamdade ${ }^{4}$, Puneet Chitlangia ${ }^{5}$

\section{HOW TO CITE THIS ARTICLE:}

Neeraj Kumar, Niharika Rathore, Hemant Shakya, Anshuman Jamdade, Puneet Chitlangia. "Cystic Degeneration in Follicular Ameloblastoma: A Case Report". Journal of Evolution of Medical and Dental Sciences 2014; vol. 3, Issue 18, May 05; Page: 4859-4865, DOI: 10.14260/jemds/2014/2524

\begin{abstract}
Ameloblastoma is a slow-growing benign neoplasm that has a strong tendency to local invasion and that can grow to be quite large without metastasizing. Rare examples of distant metastasis of an ameloblastoma in lungs or regional lymph nodes do exist. It has an aggressive and recurrent course and is rarely metastatic. Radiographically it shares common features with other lesions such as the giant cell tumor, aneurysmal bone cyst, and renal cell carcinoma metastasis; a definitive diagnosis can only be made with histopathology. It appears most commonly in the third to fifth decades and with equal frequency between sexes. Ameloblastoma prevalently occurs in the mandibular molar and ramus areas. The patients usually present late after the tumor achieved considerable size to cause facial disfigurement. Recurrence frequently appears after inadequate treatment. Here we present a case of follicular Ameloblastoma in a 55 year old female patient who presented late with a swelling on the left side of the mandible. The complete en bloc surgical excision of the lesion along with enveloping mandible was done with no recurrence till date.
\end{abstract}

KEYWORDS: Ameloblastoma, Neoplasm, Mandible, Odontogenic tumor.

INTRODUCTION: Ameloblastomas are benign locally aggressive, polymorphic neoplasms of proliferating odontogenic epithelial origin, arising from cell rests of enamel organ, either remnants of dental lamina or remnants of Hertwig's sheaths, the epithelial rest of Malassez, the developing enamel organ, basal cell epithelium of the jaws. ${ }^{1}$ Ameloblastomas constitute approximately $1 \%$ of all cysts and tumors of the jaws. The occurrence in the mandible is five times higher than in the maxilla. ${ }^{2}$

Based on the recent Classification of Odontogenic Tumors, by World Health Organization (WHO), benign ameloblastomas are recognized in four subtypes: the solid/multicystic, the desmoplastic, the unicystic and the extraosseous/peripheral type. ${ }^{3}$

The question of malignancy in ameloblastoma has been the subject of considerable discussion and controversy for many years. There can be little argument that an ameloblastoma that metastasizes is malignant, even if the tumor shows benign histological features. In other instances, ameloblastoma has been considered to be malignant on the basis of an aggressive clinical course in the absence of metastasis. These lesions often show unusual or atypical histological features. ${ }^{4}$

Several histopathologic patterns of ameloblastomas are commonly described and include the follicular, plexiform, acanthomatous, granular cell, and basal cell patterns. There appears to be rather general agreement that these variations in histopathology patterns do not have any significant bearing on prognosis except unicystic ameloblastoma because of the less aggressive behavior and favorable prognosis. ${ }^{5}$ We present a case of a large follicular mandibular ameloblastoma in a 55 year old female patient. 


\section{CASE REPORT}

CASE REPORT: A 55 yr. old female patient came to department of OMR, with chief complain of swelling in left lower posterior region of jaw since 6 months. Extraorally (figure 1)a large $8 \times 4 \mathrm{~cm}$ solitary diffuse bony hard non-tender swelling extending from symphysis menti to angle of mandible and inferiorly $1.5 \mathrm{~cm}$ below lower border of mandible, superiorly at the level of commissure of mouth with normal overlying skin in color without any sinus and drainage and there was no local rise in temperature.

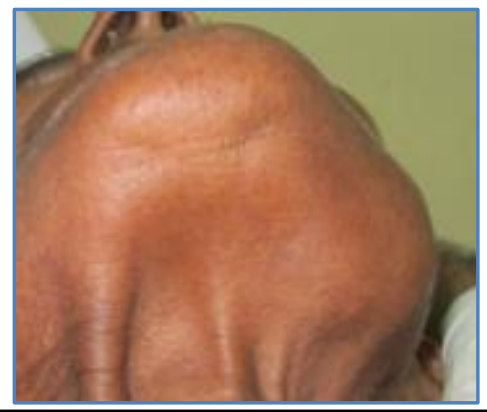

Figure 1: Extra oral view (submental view) showing swelling at left mandibular region

On intraoral (figure 2) examination a $8 \times 3 \mathrm{~cm}$ solitary, firm, non-tender swelling extending from mesial of 38 to 43 causing left lower buccal and lingual sulcus obliteration, with areas of perforation felt in anterior region.

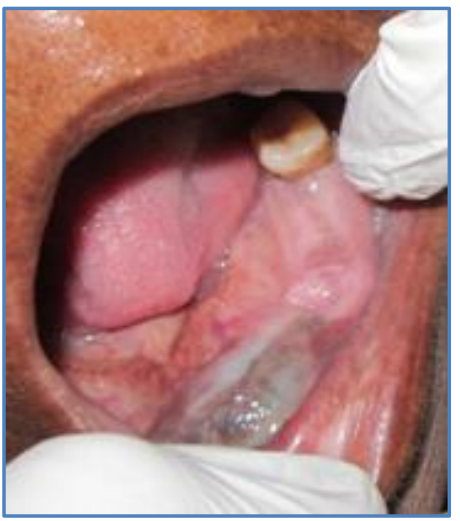

\section{Figure 2: Intra oral view showing obletration of buccal \& lingual vestibule}

Provisional diagnosis was given as odontogenic tumor with differential diagnosis as odontogenic cyst and bone tumor

Aspirate from the lesion had dark brown color fluid with $4.7 \mathrm{gm} \%$ protein level.

The details of the procedure were explained to the patient and a written informed consent was obtained. Patient was subjected to routine radiological and hematological examination. Mandibular occlusal (figure 3) showed multilocular lesion with buccal and lingual cortex expansion with perforation. 


\section{CASE REPORT}

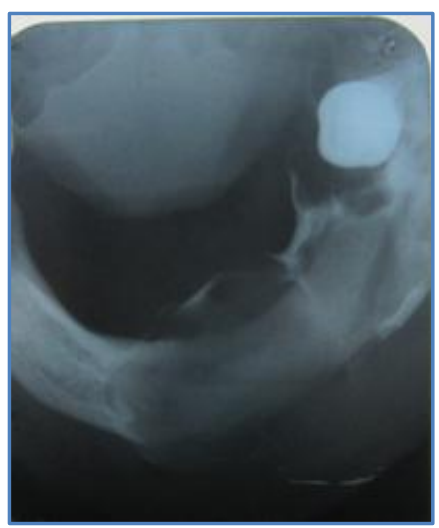

\section{Figure 3: Occlusal radiograph showing multilocular lesion with buccal and lingual cortex expansion with perforation}

The Panaromic view (figure 4) revealed multilocular radioluceny extending from ascending part of ramus to 43 region with scalloped pattern and perforation.

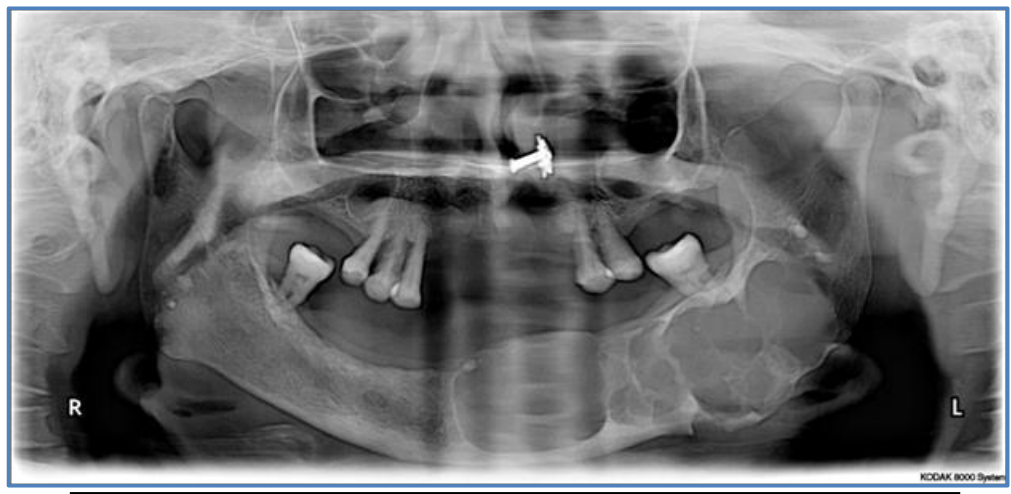

Figure 4: Panoramic view showing multilocular radiolucency crossing midline

Coronal-section (figure 5) of Contrast Enhanced CT showed a hyper dense mass size $23.8 \mathrm{~mm} \times 20.5 \mathrm{~mm}$ in left side of mandible and Axial-section (figure 6) showed $59.1 \mathrm{~mm} \times 25.4 \mathrm{~mm}$ lesion with soft tissue invasion.

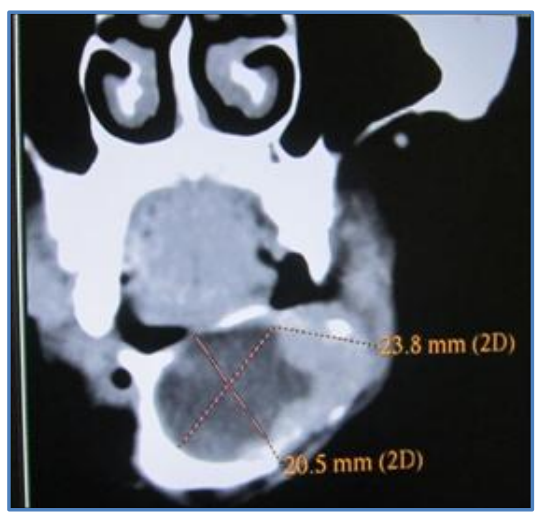

Figure 5: Coronal-section of Contrast Enhanced CT showing a hyper dense mass size $23.8 \mathrm{~mm} \times 20.5 \mathrm{~mm}$ in left side of mandible 


\section{CASE REPORT}

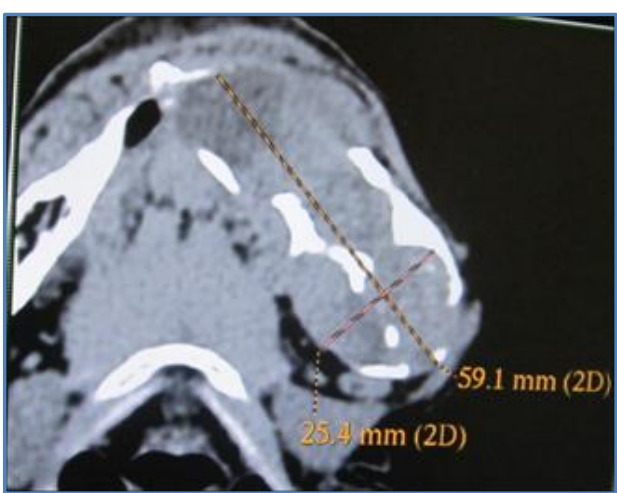

Figure 6: Axial-section showing $59.1 \mathrm{~mm} \times 25.4 \mathrm{~mm}$ lesion with soft tissue invasion

3D reconstructive CT-scan image (figure7a\&7b) revealed a $6.5 \times 3.7 \times 3.0 \mathrm{~cm}$ sized multiloculated, expansile, lytic lesion involving the body and inferior part of ramus of the left side of mandible.

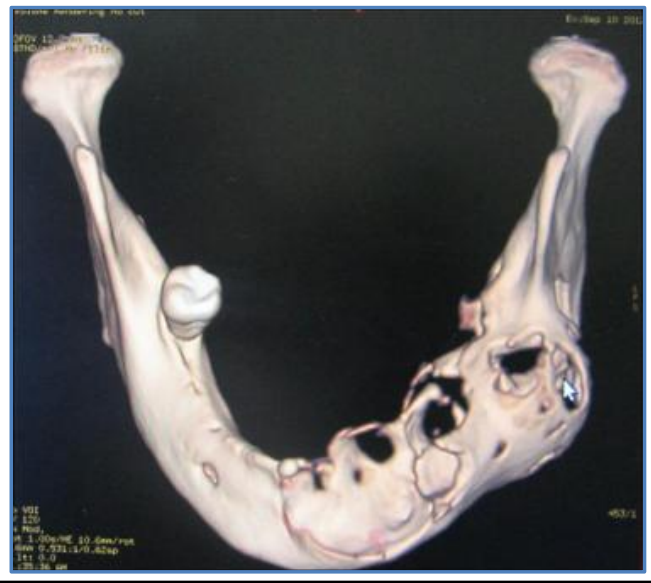

\section{Figure 7a: 3D reconstructive CT-scan image showing} bicorticle expansion with perforation

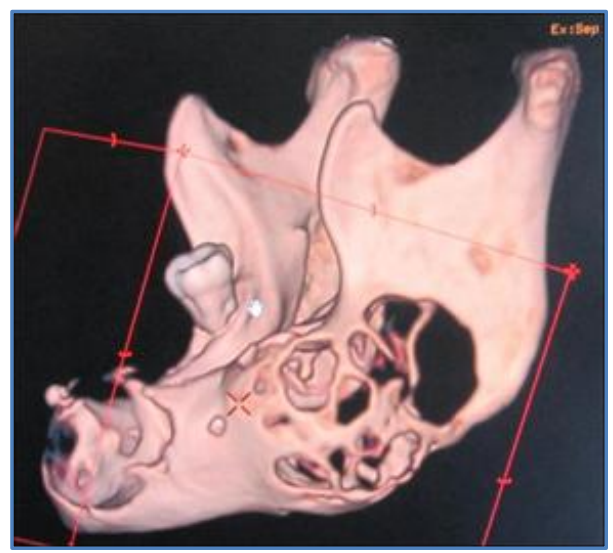

Figure 7b: 3D reconstructive CT-scan image showing bicorticle expansion with perforation 


\section{CASE REPORT}

Incisional biopsy was taken from the site which shows features of follicular ameloblastoma undergoing cystic degeneration. Then the patient was sent to oral and maxillofacial surgery where she underwent hemimandibulectomy and reconstruction was done with $2.5 \mathrm{~mm}$ reconstruction plate. Patient was discharged after 7 days.

In the histopathology (figure 8) report, a completely resected lesion showed small and large island of odontogenic epithelial cells in follicles which at many places appears to be undergoing cystic degeneration.

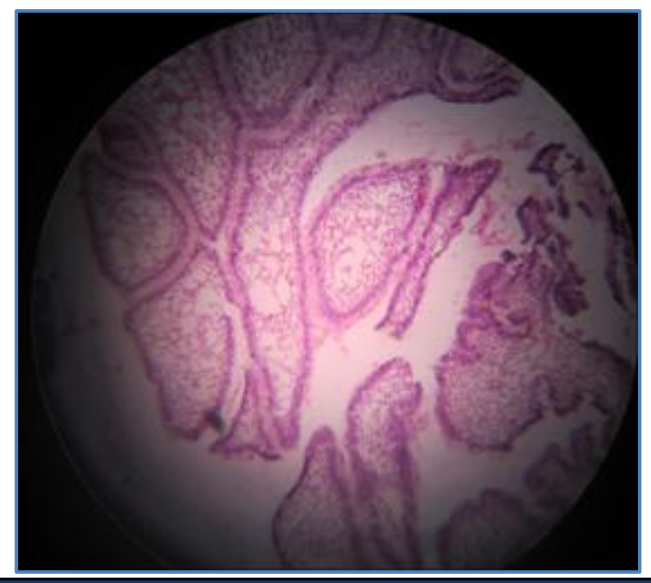

\section{Figure 8: Photomicrograph shows island of odontogenic} epithelial cells in follicles with cystic degeneration

Patient had no signs of recurrence after 8 months follow up (figure 9).

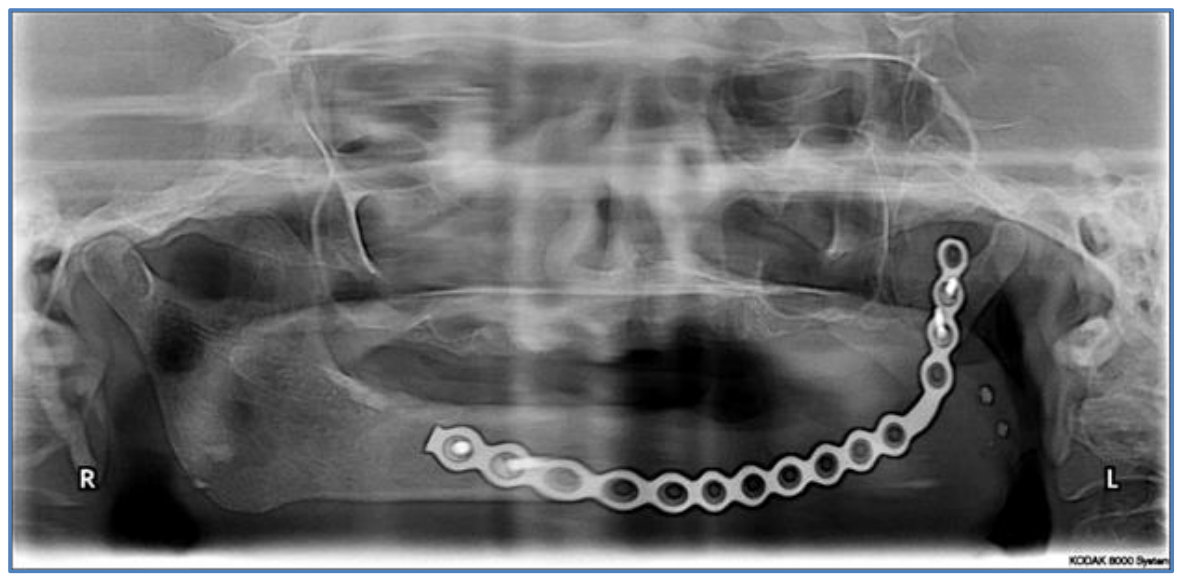

Figure 9: Panoramic view after 8 months

DISCUSSION: Ameloblastoma is a benign epithelial odontogenic tumor but is often aggressive and destructive, with the capacity to attain great size, erode bone and invade adjacent structures. ${ }^{6}$ Radiographically it may appear unilocular or multilocular with soap bubble or honeycomb appearance; buccal and lingual expansion of the cortex invariably accompanies ameloblastoma. Thinned and intact cortex shows egg shell appearance. ${ }^{7}$ Worth divided the ameloblastoma into four radiological manifestation categories. 


\section{CASE REPORT}

1. First, resembling a dentigerous cyst without septa, mostly in ramus region. Most frequently anterior wall of ramus lost.

2. Second, most common, cystic appearing cavity with distinctive septa (caricature of spider). Perforation in anterior surface of ramus \& superior border of the body of mandible. Characteristically, angle of mandible is preserved. The inferior aspect may be ballooned out with a significant smooth downward convexity.

3. Third, less common multilocular cystic appearance in posterior portion of mandible and ramus. Significant downward enlargement of inferior border of mandible, which maintains a convex lower border.

4. Fourth, solid varity in which normal bone is replaced by honeycomb appearance in which cavities are relatively small and fairly uniform in size.

Ameloblastoma is usually included in the differential diagnosis according to the presentation of the patient's history and clinical characteristics. The diagnosis of ameloblastoma is suggested by nonspecific radiographic findings and a thorough locoregional physical examination. Nevertheless, a definitive diagnosis is only obtained through a histopathological exam.

The persistent growth pattern (localized and infiltrative to the maxillofacial region) and the ability to produce pronounced deformities are clinical characteristics that contribute to the possible identification of ameloblastomas. The typical ameloblastoma begins as a slowly destructive asymptomatic and intraosseous expansion, being a lesion that tends to expand and infiltrate, rather than perforate the bone. However, the diagnosis can also be suggested through a routine radiographic examination. As observed in the above mentioned case, unless the tumor becomes infected, it is rarely painful. When these tumors become symptomatic, the patient may experience pain or numbness, swelling, malocclusion, tooth mobility or secondary infection.8, 910

CONCLUSION: Ameloblastoma is considered to be a benign, but locally invasive odontogenic tumor with a high rate of recurrence. Essentially, most studies showed that the prognosis for ameloblastoma is more dependent on the method of surgical treatment rather the histologic type of tumor.

Resection with some safe margin (marginal, segmental or composite resection depending on the site and size of the lesion) is the best primary method for treating solid/multicystic Ameloblastomas to avoid recurrence.

\section{REFERENCES:}

1. Hennry M. Cherrick. "Odontogenic tumors of the jaw," in Oral and Maxillofacial Surgery. Daniel M. Laskin, Ed., pp. 626-636, AITBS, New Delhi, India, 2009.

2. I. A. Small, C. A. Waldron. Ameloblastoma of the Jaws. Journal of Oral and Maxillofacial Surgery and Pathology, vol. 8, pp. 281-297, 1995.

3. Thompson L. World Health Organization classification of tumours: pathology and genetics of head and neck tumours. Ear Nose Throat J 2006; 85:74. [16579185]

4. Mubeen K, Shakya HK, Jigna VR. Ameloblastic Carcinoma of Mandible: A Rare Case Report. J Clin Exp Dent. 2010;2(2):e100-4 


\section{CASE REPORT}

5. Shakya H, Khare V, Pardhe N, Mathur E, Chouhan M. Basal Cell Ameloblastoma Of Mandible: A Rare Case Report With Review. Case Rep Dent. 2013; 2013:187820. doi: 10.1155/2013/187820. Epub 2013 Apr 8.

6. Iordanidis S, Makos C, Dimitrakopoulos J, Kariki H. Ameloblastoma of the maxilla. Case report. Aust Dent J. 1999; 44:51-5.

7. R. P. Langland, O. E. Langland, C. J. Nortje. Diagnostic Imaging of the Jaw, Williams \&Wilkins, Philadelphia, Pa, USA, 1st edition, 1995.

8. Anjos E, Andrade E, Pinto L, Souza L. Estudo clinicopatologico de ameloblastomas: analise de casos. Rev Bras Patol Oral, 60:224-8, 2003.

9. Antunes A A, Silva P V, Antunes A P, Romualdo Filho J. Ameloblastoma: Estudo Retrospectivo. Rev Bras Cir Cabe?a Pesco?o, 35:70-3, 2006

10. Medeiros M, Porto G G, Laureano Filho J R, Portela L, Vasconcellos R H. Ameloblastoma em mandibula. Rev Bras Otorrinolaringol., 74:478, 2008.

\section{AUTHORS:}

1. Neeraj Kumar

2. Niharika Rathore

3. Hemant Shakya

4. Anshuman Jamdade

5. Puneet Chitlangia

\section{PARTICULARS OF CONTRIBUTORS:}

1. Final Year Post Graduate, Department of Oral Medicine and Radiology, Mahatma Gandhi Dental College, Jaipur.

2. Final Year Post Graduate, Department of Medicine and Radiology, Mahatma Gandhi Dental College, Jaipur.

3. Assistant Professor, Department of Oral Medicine and Radiology, Mahatma Gandhi Dental College, Jaipur.
4. Professor, Department of Oral Medicine and Radiology, Mahatma Gandhi Dental College, Jaipur.

5. Assistant Professor, Department of Oral and Maxillofacial Surgery, Mahatma Gandhi Dental College, Jaipur.

\section{NAME ADDRESS EMAIL ID OF THE CORRESPONDING AUTHOR:}

Dr. Hemant Shakya, Department of Oral Medicine and Radiology, Mahatma Gandhi Dental College, Jaipur - 302022.

E-mail: shakyamds@gmail.com

Date of Submission: 07/04/2014. Date of Peer Review: 08/04/2014. Date of Acceptance: 21/04/2014. Date of Publishing: 01/05/2014. 